\title{
Public Health Concerns of Environmental Exposure Connected with Female Infertility
}

\author{
Boma F. Eddie-Amadi ${ }^{1}$, Chinyere S. Dike ${ }^{2}$ and Anthonet N. Ezejiofor ${ }^{2,3}$ \\ ${ }^{1}$ African Centre of Excellence, Centre for Oilfield Chemicals Research (ACE-CEFOR), University of Port \\ Harcourt, PMB, 5323 Port Harcourt, Choba, Nigeria. \\ ${ }^{2}$ Africa Centre of Excellence, Centre for Public Health and Toxicological Research (ACE-PUTOR) University \\ of Port Harcourt. \\ ${ }^{3}$ Department of Experimental Pharmacology \& Toxicology, Faculty of Pharmacy, University of Port Harcourt, \\ PMB, Port Harcourt, Choba 5323, Nigeria. \\ *Corresponding author email: dike.chinyere@uniport.edu.ng
}

\begin{abstract}
This study reviewed recent articles on the prevalence and risk exposure of pollutants connected with female sterility. Occupational and regular exposure to metals and other chemicals causes oxidative stress, which causes hormonal imbalance and results in cell membrane damage, cell apoptosis, protein, lipid, and nucleic acid damage, reduced oocyte growth and development, increased mRNA in the anterior pituitary, poor oocyte quality, poor reproductive outcome, damage DNA, embryo fragmentation, implantation failure, abortion, and ovarian cancer. This study revealed an association between environmental contaminants and unexplained infertility, women with unexplained infertility have decreased ovarian sensitivity to gonadotropins, resulting in higher circulating gonadotropin levels, including higher mean serum follicle-stimulating hormone (FSH) and luteinizing hormone ( $\mathrm{LH})$ levels. Aside from the effects of environmental contaminants on female infertility, they may also increase the risk of spontaneous abortion, stillbirths, premature delivery, gestational diabetes mellitus, pregnancy hypertension, preeclampsia, premature rupture of membranes, intrauterine growth restriction, low birth weight, and harm to the growing baby, resulting in foetal abnormality and congenital disabilities. Heavy metal risk exposures should be decreased to a minimum or zero level to treat female infertility.
\end{abstract}

Keywords: $\quad$ Fertility, metal mixture, endocrine disruptors, prevalence, endometriosis

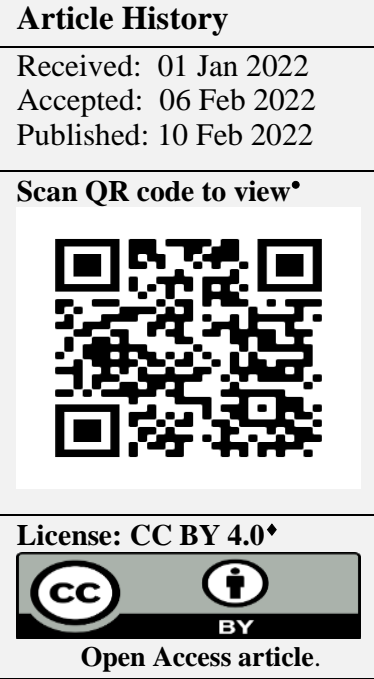

Open Access article.

How to cite this paper: Eddie-Amadi, B.F., Dike, C.S. and Ezejiofor, A.N. (2022). Public Health Concerns of Environmental Exposure Connected with Female Infertility. IPS Journal of Public Health, 1(1), 16-26. https://doi.org/10.54117/ijph.v1i1.1.

\section{Introduction}

Female infertility is a common condition of the reproductive system that often lead to the failure of a woman to get pregnant after years of regular and unprotected sex and without birth control (Wang et al., 2019; Borght \& Wyns, 2018). The WHO defined infertility as the failure of a couple who are active sexually to reproduce within the period of 1 year or more. The WHO reported that over 180 million couples face the costs of infertility/sterility (WHO, 2018). An estimate of $8-15 \%$ of couples of childbearing age suffers infertility globally (Sun et al., 2019; Henriques et al., 2019). Another report by WHO posited from 1990 to 2010, the total burden of women sterility from 190 countries is similar in estimated levels and trends (Ma et al. 2018).

There are two common types of infertility namely; primary and secondary infertility. Primary infertility/sterility is the inability of a woman to get pregnant after twelve months of sex devoid of birth control methods while secondary infertility is referred to as the inability to conceive after an initia pregnancy. Secondary infertility is a common condition around the globe, usually caused by unsafe abortions, poor maternity care and reproductive tract infections (if left unattended may damage the fallopian tube causing irreversible tubal blockages (Inhorn \& Patrizio 2015). Adeoye et al. (2018) estimated that 48 million women from South Asia, Sub-Saharan Africa, North Africa, the Middle East, Central Europe and Central Asia suffers the highest.

The causes of infertility include endometriosis, polycystic ovary syndrome, ovulation dysfunction, abnormal uterus or fallopian tube, primary ovarian insufficiency, pelvic adhesions, pelvic inflammatory diseases, tubal blockage, tuboperitoneal abnormalities, myomas distorting the uterine cavity, congenital uterine anomalies, cystic fibrosis and others (Hung et al., 2016; Wang et al., 2019). Environmental contaminant exposure could lead to all these causes mentioned acting as a precursor to causes of female infertility.

Infertility is recognised by WHO as a public health concern globally which has generated into grave health challenge, especially in developing countries. Over 186 million people contend with the problem of infertility globally, with majority from developing countries (Borght and Wyns, 2018). One out of seven women in the western countries suffers from infertility as against one out of four women in the developing countries (Borght and Wyns 2018). The total Infertility rate has been increasing since 1990 . A careful investigation of 195 countries from 1990 to 2017 showed that infertility increased by $0.370 \%$ per year for females of reproductive age. This was found highest in the SubSaharan Africa, North Africa, Central and Eastern Europe, South and Central 
Asia, and Middle East regions which may have reached 30\% (Mascarenhas et al., 2012). Notably, growing older is accompanied with decrease in fertility rate. A study showed that women of within the ages of 35-39 had the highest prevalence rate while age group within 15-19 had the lowest (Sun et al., 2019).

\section{Effect of Environmental Contaminant on Female Infertility}

In females, exposures to environmental toxicants revealed that its effect on the female reproductive functions ends in infertility (Gopinath, 2013). Persisten organochlorine pollutants, increased perfluorochemicals levels, phthalate esters, and intra-uterine exposure to cigarette smoke are environmental factor that causes endometriosis. These factors caused induced oxidative stress, varying hormonal homeostasis, or by changing immune responses (Dai et al., 2018). This review will focus more on endocrine-disrupting chemicals and heavy metals. Environmental chemicals, known as endocrine disruptors, have the capacity to mimic, block or modulate the endocrine system through the interaction with steroidal receptors. Recently, ubiquitous environmenta contaminants have been proposed to have a role in the prevalence of endometriosis (Barbosa et al., 2011). Several studies suggested that women occupationally and environmentally exposed to individual heavy metals such as Lead, Mercury, Aluminium, Manganese, Cadmium, Arsenic or mixtures of metals had reduced fertility, high prevalence and incidence rates of menstrua disorders (Osmel and Jose 2020). Growing data shows an association between heavy metals and unexplained infertility. Studies reveal higher levels of heavy metals in urine, hair and blood of women with unexplained infertility than fertile ones (Henriques et al., 2019).

\section{i. Endocrine-disrupting chemicals (EDCs) and female reproductive} health

An endocrine disruptor is defined as "an exogenous chemical, or blend of chemicals, that can impede with any aspect of hormone action. An estimate of 1000 chemicals is recognised as potential endocrine disruptors (Street et al. 2018). Endocrine-disrupting chemicals are chemicals that have the ability to alter or modify the endocrine system of wildlife and humans at ecologically relevant thresholds. There are everyday chemicals that exhibit endocrine disrupting features in both animals and humans, which result in infertility, improper hormone production, subfertility, menstrual cycle abnormalities, and estrous, anovulation, and early reproductive senescence (Rattan et al., 2017). They include plasticisers as bisphenol A, phthalates, flame retardants, industrial chemicals including alkylphenols, heavy metals and dioxins, ai pollutants such as polycyclic aromatic hydrocarbons, and pesticides. Smith $e$ al., (2013) demonstrated that exposure to propylparaben (PP) a potentia endocrine disruptor could lead to reduced ovarian reserve and increased ovarian aging among women.

Endocrine-disrupting chemicals can activate, block, or alter synthesis and degradation of hormone by binding to endocrine receptor, resulting in irregular hormonal signals that could increase or inhibit normal endocrine function (Street et al., 2018). EDCs influence hormonal balance and thereby disrupting the function ovarian function, including fertility (Gopinath, 2013). Curren studies point to EDC-induced reproductive disorders have been linked with DNA modification (mostly DNA methylation). Investigation by Petro et al. (2012) revealed that human follicular fluid exposed to EDCs an Polychlorinated Biphenyls (PCBs) decreased IVF successes and developmen of oocyte into embryos of high-quality.

\section{a. Polychlorinated Biphenyls (PCB)}

Polychlorinated biphenyls are environmental toxin which often comprise of endocrine disrupting activity. PCBs are stable, lipophilic compounds that build up in the surroundings and in food chains. In females, PCB has been connected with reproductive disorder. In one in vitro study, data showed PCB congeners can lead to an increase in mRNA at $0.01-100 \mu \mathrm{M}$ and then reduced peptide levels of gonadotropin releasing hormone $(\mathrm{GnRH})$ in hypothalamic mouse cells and also caused increase apoptosis in hypothalamic GnRH containing cells in a non-monotonic manner (Bell, 2014). Studies has shown that reduced fertility in women and animals is related with exposure to PCB. In women consuming contaminated fish, shorter menstrual cycles and gestation was related with moderate to high PCB exposure (Craig et al., 2011 Dallaire et al., 2013). Kezios et al. (2012) established that mono-ortho and diortho exposure to PCB is connected with reduced gestational. Also, PCB exposure $(12.5-50 \mathrm{mg} / \mathrm{kg})$ showed increased apoptosis of cumulus cells, inhibits parthenogenetic activation and maturation of mouse oocytes (Liu $e$ al., 2008), and affects in vitro fertilization in females.

\section{b. Bisphenol A (BPA)}

BPA is highly produced chemical extensively used in the manufacture of various consumer products such as toilet papers, envelopes, printer ink, processed foods, toys, cell phones, polycarbonate plastics, dental fillings, CDs, DVDs, medical devices, paint, epoxy resin liners of canned foods and thermal receipts (Mínguez-Alarcón and Gaskins, 2017; Rashtian et al., 2019). BPA has endocrine disrupting properties with the capability to impinge on multiple hormonal pathways. It also has the capacity to bind to estrogen receptors and initiate cellular responses similar to those caused by estradiol (Street et al., 2018).

Experimental studies have shown association between BPA and abnormal changes in women reproductive system. Markey et al. (2005) exposed female mice utero to BPA via pumps implanted into pregnant dams, the result showed exposure to BPA causes alteration in development of female reproductive organs. Exposure to BPA revealed elevated expression of endometrial ER- $\alpha$, reduced volume of endometrial lamina propria, decreased progesterone receptor and vaginal weight (Rashtian et al., 2019). Hormone synthesis (progesterone and estradiol), mRNA and protein expression of cholestero side-chain cleavage enzyme (CYP11A), 3 $\beta$-hydroxysteroid dehydrogenase (HSD), and aromatase (CYP19A1) are also altered by BPA (Mansur et al. 2016; Rashtian et al., 2019). Several investigations have found BPA exposure to be connected with women having PCOS. Cross-sectional survey between women suffering from PCOS $(n=71)$ and those without PCOS that were matched by age and BMI (control group $n=100$ ). The outcome revealed higher BPA level in the blood of women with PCOS than BPA levels in the blood of women without PCOS (Kandaraki et al., 2011).

Furthermore, BPA exposure can alter reproductive outcome in infertile women undergoing IVF treatment. Ehrlich et al. (2012) associated increased BPA with decreased oocytes retrieved, less mature metaphase II oocytes, less normal fertilized oocytes, reduced serum E2 levels, and tendency of having lower blastocyst formation. Similar study conducted by Mok-Lin et al. (2010) reported that 84 women who participated in 112 IVF cycles showed relationship between high urinary BPA and poor ovarian response, which was revealed by less oocytes retrieved per cycle and lower serum E2 levels. Hence, elevated urinary BPA can result to decrease oocyte maturation and reduction in female fertilization. Additionally, frequent loss of pregnancy has been linked to exposure to BPA exposure. A case control study in eastern China, showed higher BPA levels in women with recurring miscarriages than women not exposed to BPA (Shen et al., 2015).

\section{c. Triclosan}

Triclosan is a lipid emulsifiable phenolic composite with wide spectrum antibacterial characteristics (Mínguez-Alarcón and Gaskins 2017). It is used in personal care products such as toothpaste, air fresheners, anti-bacterial soap, deodorants, surgical scrubs, mouthwash, sanitizers and sutures (Fang et al. 2010), and their usage portend their absorption (Yang et al., 2015). Triclosan functions as an anti-estrogen or anti-androgen with likely undesirable effects on reproductive outcomes (Mínguez-Alarcón and Gaskins, 2017).

Usage of triclosan has been connected with female infertility and abnorma reproductive effect and reduced ovary weight (Velez et al., 2015). Similarly, subcutaneous administration of triclosan (18 and $27 \mathrm{mg} /$ day) into uteri of adult rats result to low number of implantation sites (Crawford and Decatanzaro, 2012). Also, reduced gravid uterine weights were observed when rats were exposed to triclosan (30-600 $\mathrm{mg} / \mathrm{kg}$ per day) orally, reduced prolactin, estradiol, progesterone and testosterone levels were reported. (Feng et al., 2016).

\section{d. Parabens}

Parabens is a bunch of alkyl esters of p-hydroxybenzoic acid that is utilized as anti-microbial preservatives in cosmetics, personal care products, pharmaceuticals and foods (Rattan et al., 2017; Andersen, 2008; National Toxicology program, 2005). Parabens exposure occurs through ingestion, inhalation, or dermal absorption. Parabens are chemicals that interrupt endocrine functioning, affecting female fertility rate. Studies have described parabens to have binding ability with estrogen receptor, however, rodent toxicity studies described the effects parabens have on female reproductive functioning, as well as reduced ovarian weights and cause changes in histopathology of ovaries (Taxvig et al., 2008; Vo et al., 2010; Smith et al., 2013; Mínguez-Alarcón and Gaskins, 2017). Decreased counts of antral follicle in humans have been connected with elevated levels $(87.8-727 \mu \mathrm{g} / \mathrm{L})$ of propylparaben (Smith et al., 2013). A study by Japanese researchers revealed that short menstrual cycles in females were connected to high urinary estrogen equivalent to total and butyl paraben concentrations (Nishihama et al., 2016). Furthermore, subcutaneous administration of parabens (6-210 $\mathrm{mg} / \mathrm{kg}$ ) in ovariectomized mice caused increased uterine weight (Lemini et al., 2003), also, isobutylparaben (about $4.36 \mathrm{mg} / \mathrm{L}$ per day) increased dam uterine weights in rats (Kawaguchi et al. 2009). Additionally, in women, high urine 
butylparaben were linked with lowered estradiol and reduced showed a decrease in ER- $\beta$ expression in the ovaries of the female foetus. estradiol/progesterone ratio (Aker et al., 2016; Rattan et al., 2017). Exposure However, no change was observed in levels of ovarian estradiol or ovarian to paraben may lead to diminished ovarian reserve, contribute to ovarian aging histopathology (Smith et al., 2013). Table 1 summarizes the different among women at an infertility clinic and affect pregnancy adversely. Taxvig endocrine-disrupting chemicals and it effects in female infertility. et al. (2008) reported that pregnant rats subcutaneously exposed to parabens

Table 1: Endocrine disrupting chemicals effect on females

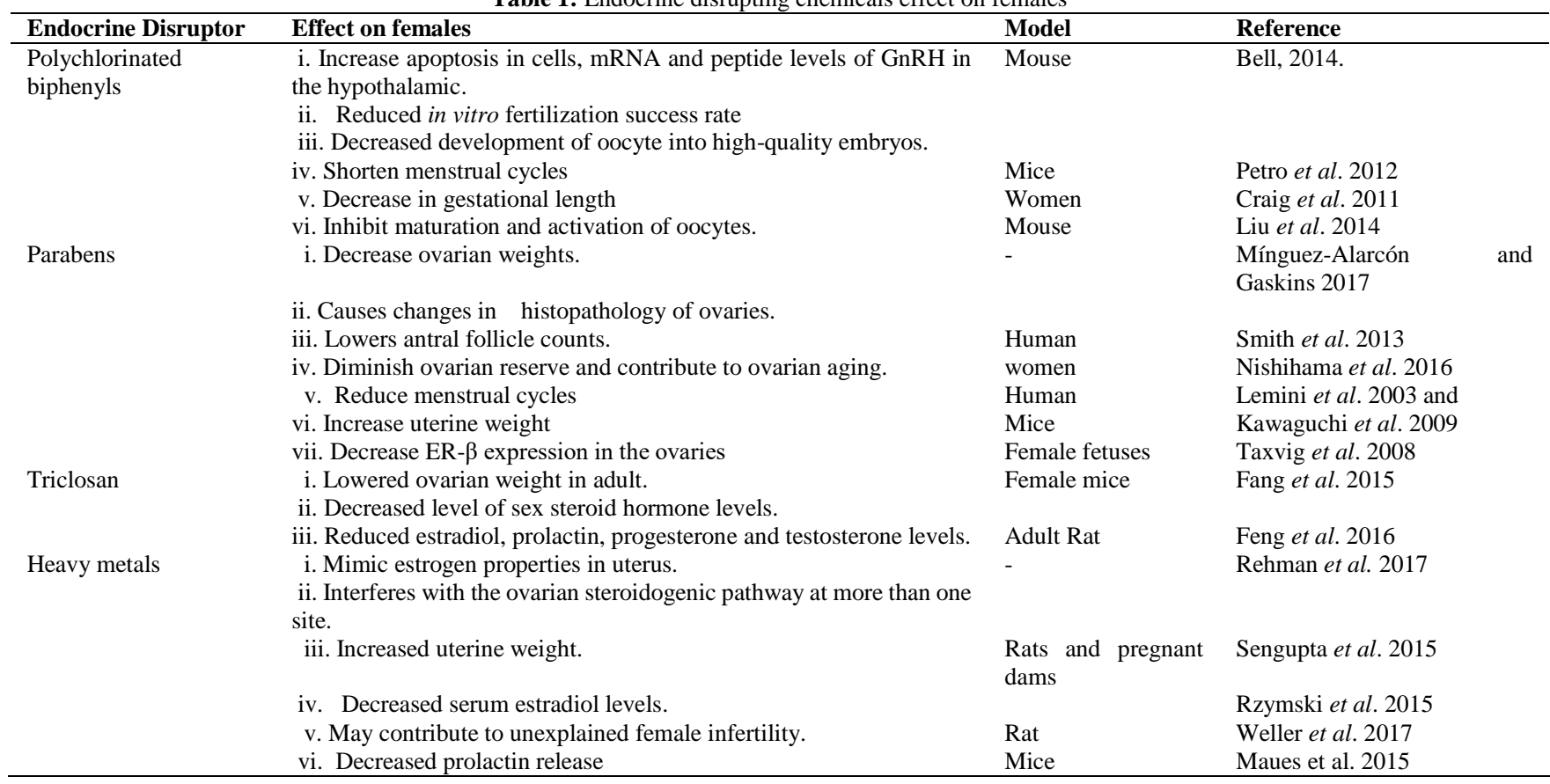

ii. Heavy Metals and Female Infertility

The resulting effect of heavy metals on female reproductive health is of a great burden. Human exposures to heavy metals usually happen occupationally, environmentally, or through dietary intake (Ma et al., 2018, Amaya et al., 2013). Several studies suggested that women occupationally and environmentally exposed to individual heavy metals such as Lead, Mercury, Aluminium, Manganese, Cadmium, Arsenic or mixtures of metals had reduced fertility, high prevalence and incidence rates of menstrual disorders (Osmel and Jose 2020; Maeda et al., 2019, Susko et al., 2017; Sengupta et al. 2015; Sengupta and Dutta 2018; Henriques et al., 2019). Exposure to heavy metals could also be associated with amenorrhoea, Polycystic Ovary Syndrome, premenstrual syndrome, early menopause, dysmenorrhoea (menstrual pain), endometriosis, benign breast disorders and galactorrhoea, these can be related to female infertility (Bjorklund et al., 2019).

Heavy metals even at a low level of exposure may have deleterious effects on female fertility (Lee et al., 2020; Osmel and Jose 2020). Latest study showed mixtures of heavy metals may affect female fertility. An investigation carried out revealed positive association with self-reported infertility and low level of blood lead and cadmium $(\mathrm{Pb}=0.50 \mu \mathrm{g} / \mathrm{dL}$ and $\mathrm{Cd}=0.26 \mu \mathrm{g} / \mathrm{L})$ after adjusting for confounding factors (odds ratio (OR) for $\mathrm{Pb}$ per two-fold increase in blood metal levels $=2.60 ; 95 \%$ confidence interval $(95 \% \mathrm{CI}), 1.05-6.41$ and OR for cadmium per two-fold increase $=1.84 ; 95 \%$ CI, 1.07-3.15) (Lee et al., 2020) Heavy metals even at a low level of exposure may have deleterious effects on female fertility (Osmel and Jose 2020). Growing data shows an association between heavy metals and unexplained infertility. Studies reveal higher levels of heavy metals in urine, hair and blood of women with unexplained infertility than fertile ones (Henriques et al., 2019; Altunkaynak et al., 2016). Although very few studies have examined the relationship between heavy metal exposures and female fertility outcomes. Heavy metals such as aluminium lead, manganese, cadmium, mercury and arsenic have reproductive toxicity (Sengupta et al., 2015). Studies postulate heavy metal exposure increases the risk of spontaneous abortion, miscarriage, fetal malformation, placenta insufficiency, and premature birth (Rzymski et al. 2015, Sengupta et al., 2015 Susko et al., 2017). A study by Quansah et al. (2015) found significan association between spontaneous abortion with high levels of As in drinking water and blood $\mathrm{Pb}$ levels (As in drinking water OR: $1.98,95 \% \mathrm{CI}: 1.27,3.10$ and blood $\mathrm{Pb}$ levels OR: $1.8,95 \% \mathrm{CI}: 1.1,3.1$ for every $5 \mu \mathrm{g} / \mathrm{dL}$ increase in blood $\mathrm{Pb}$ ).
Furthermore, women with unexplained infertility have decreased ovarian sensitivity to gonadotropins, resulting in higher circulating gonadotropin levels, including higher mean serum FSH and luteinizing hormone (LH) levels (Lei et al., 2015). Asides from heavy metals effects on infertility in females, exposure to heavy metals could also increase the risk of suffering spontaneous abortion, stillbirths, premature delivery, gestational diabetes mellitus, pregnancy hypertension, preeclampsia, premature rupture of membranes, intrauterine growth restriction, low birth weight, harm the growing baby leading to foetal abnormality and congenital disabilities such as cleft lip/palate and other pregnancy complications in pregnant women (Osmel and Jose 2020; Cheng et al., 2017; Maeda et al., 2019; Itai et al., 2004; Kumar, 2018; Yorifuji et al., 2017).

Lead $(\mathbf{P b})$ effect on female reproduction

Lead is a heavy metal that is both harmful to human and animal's health. Industrial activities like burning of fossil fuel, mining, production of lead-acid batteries, pigments, paints and various manufacturing processes contribute greatly to $\mathrm{Pb}$ increase in the environment (Rehman et al., 2017). The effect of $\mathrm{Pb}$ could result in impairment of the female reproductive system to function properly.

To establish the correlation between heavy metals and female infertility, the $\mathrm{Pb}$ level in 33 infertile women and 32 fertile women were compared. Endometrial samples were collected at 20-24 days of the menstrual cycle by endometrial biopsies, and $\mathrm{Pb}$ concentrations in the endometrium were then measured. It was discovered that $\mathrm{Pb}$ was $15 \%$ in endometrial samples of infertile women, but only $3 \%$ in endometrial samples of fertile women. Thus, it was revealed that $\mathrm{Pb}$ exposure level could induce reproductive toxicity and result in women becoming infertile.

New studies also have shown that lead could be harmful even at its low threshold exposures. In a study, Chang et al. (2006) compared women with blood $\mathrm{Pb}$ level $\leq 2.5 \mu \mathrm{g} / \mathrm{dL}$ and women with blood lead level $>2.5 \mu \mathrm{g} / \mathrm{dL}$, the result revealed that infertile women had greater blood $\mathrm{Pb}$ level than controls $(3.55 \mathrm{vs} 2.78 \mu \mathrm{g} / \mathrm{dL})$. Thus, $\mathrm{Pb}$ was associated with a threefold elevated risk for infertility, after adjusting for various confounding factors. These findings suggest an important role of even low blood lead level in the risk of infertility in women (Chang et al., 2006). An investigation performed by Rahman et al. (2013) on blood $\mathrm{Pb}$ levels in females with unexplained infertility ranging from 18-40 years revealed the mean blood level of lead was significantly higher in 
case group than that in control group $(130.0 \pm 45.2$ vs. $78.3 \pm 36.4 \mu \mathrm{g} / \mathrm{L}$, $(\mathrm{p}<0.001)$.

A study by Tang and Zhu (2003) reported that female workers exposed to $\mathrm{Pb}$ were found to have significant elevated blood lead level than in control resulting in polymenorrhea, prolonged and abnormal menstruations and hypermenorrhea. Likewise, another survey conducted in women undergoing IVF treatments in Taranto, Italy, an environment recognised as heavy meta contaminated area, by industrial processes found decreased number of mature oocytes retrieved, significant rise of follicular fluid concentration of several heavy metals, including $\mathrm{Pb}$ in women from Taranto. Additionally, recent study by Lee et al. (2019) revealed that lead exposure was positively connected with elevated serum FSH concentrations $(\beta=2.929, \mathrm{p}=0.019)$ in postmenopausal women. High levels of serum FSH could indicate poor ovarian function. Therefore, lead exposure result in decrease female fertility via reduced oocytes number, menstrual cycle disturbances, delayed conception time, changing hormonal production, circulation, affecting pregnancy, low gestational weight, premature birth and miscarriages (Kumar 2018; Lee et al., 2020).

\section{ii. Mercury (Hg) effect on female reproduction}

Mercury has been identified as a neurotoxicant as well as immunotoxic and designated by the WHO as one of the ten most dangerous chemicals to public health (Bjørklund et al., 2017). Methyl mercury exposure even at low level can have a reproductive toxicity. A study carried out by Maeda et al. (2019) showed significant link of infertility with elevated mercury and reduced selenium levels. Females with higher $\mathrm{Hg}$ level were found to have decrease luteinizing hormone ( $\mathrm{LH})$, estradiol, progesterone and prolactin levels (Henriques et al., 2019). Methyl mercury (at exposures as low as $1 \mathrm{mM}$ for 2 h) also decreased prolactin release (Maues et al., 2015).

Occupational exposure to mercury may lead to decline fecundity. As reported by Wright et al. (2015) dental care professionals who carry out procedures that exposed them to $\mathrm{Hg}$ showed reduced fertility (fecundability ratio (FR): 0.63 , $95 \%$ CI: $0.42,0.96)$. Mercury is also responsible for irregular menstruation, severe dysmenorrhea, spontaneous abortion and fetal birth defects (Ma et al. 2018; Liu et al., 2008). In a case control study in Hong Kong, Choy et al. (2002) found that blood $\mathrm{Hg}$ concentrations in women with unexplained infertility were significantly higher than those in women with normal fertility

\section{iii. Manganese (Mn) effect on female reproduction}

Manganese is a trace element that is a major component of life, usually needed for normal physiology and is commonly found in food. However, information or data to link the possible effect of Manganese and infertility is limited. Places such as dried battery cell factories and mines are potential places for occupational exposure to manganese.

Overexposure to manganese chloride cause grave fertility abnormalities, developmental toxicity, neurotoxicity, and immunotoxicity. In rats, manganese exposure may likely reduce the number of follicles in the ovaries and induced persistent corpora lutea (Sengupta et al., 2015). Pine et al. (2005) as well reported that rats exposed to $\mathrm{Mn}$ for 4 or 13 weeks showed a progressive and significant decrease in hypothalamic dopamine (DA), while prolactin and pituitary transcription factor-1 messenger RNA (Pit-1 mRNA) levels increased in response to Manganese exposure.

\section{iv. Aluminium (Al) effect on female reproduction}

Aluminium is categorized as toxic heavy metal that has no biological function in living organisms (Miska-Schramm 2016). There are limited studies associated with aluminium and its effects on female reproduction. However, a few data suggest that aluminium exposure inhibit reproductive function in female rats. Wang et al. (2012) examined the effects of aluminium exposure on the reproductive function in female rats. The results showed decrease levels of estrogen, progesterone, FSH, and LH. Whereas increased testosterone level in the low and medium dose groups $(\mathrm{P}<0.05)$. Similarly, Miska-Schramm et al. (2016) studied the effect of aluminium exposure on reproductive ability in the bank vole. The results reveals that in females treated with $3 \mathrm{mg} / \mathrm{l} \mathrm{Al}$, had increased uterus weight higher than control $(\mathrm{p}<0.05)$.

\section{v. Cadmium (Cd) effect on female reproduction}

Environmental exposures to cadmium can lead to hormonal imbalance in females. Studies demonstrated $\mathrm{Cd}$ has estrogen-like effect, which can act as an endocrine disruptor strongly affecting the female reproductive organ in diverse ways. $\mathrm{Cd}$ at nanomolar level shows xenoestrogenic activities by persuading cell growth and motivating prolactin excretion from anterior pituitary cells in an estrogen receptor-dependent manner. As well, Cd acted as an effective xenoestrogen that can play a significant role in the causation of various pathologies of the anterior pituitary and estrogen-responsive tissues that represent a risk to human health (Kumar and Sharma 2019). It was also speculated that $\mathrm{Cd}$ may cause unexplained infertility. A case-control study showed that the levels of FSH were significantly positively correlated with $\mathrm{Cd}$ concentrations in women's serum (Gallagher et al., 2010).

Rats exposed to cadmium oxide dusts had increased duration of the estrous cycle, decreased pre-ovulatory luteinizing hormone levels in blood, and inhibited ovulation (Sengupta et al., 2015). Cd exposure to rodents resulted in a down regulation of pituitary hormones including gonadotropins, prolactin (PRL), adrenocorticotropin hormone, growth hormone, and thyroidstimulating hormone (Miler et al., 2010). According to Sengupta, Cadmium exposure up regulated the progesterone receptors and affects production of progesterone and testosterone in proestrous rats and pregnant dams, therefore, cadmium interferes with the ovarian steroidogenic pathway at more than one site (Sengupta et al., 2015). An investigation carried out by Weller et al. to evaluate the effects of cadmium exposure on female infertility parameters in mice, showed that exposure to cadmium was associated with significantly decreased serum levels of estradiol. Outcome of the study reveals that cadmium might contribute to unexplained female infertility (Weller et al., 2017). Long term Cd exposure at environmental levels is also allied with high serum FSH in US women aged 42-60 years. Also, Zheng et al. (2015), disclosed increase in Cd levels is linked with a $21 \%$ increase in early follicular phase estradiol levels (each $1 \mu \mathrm{g} / \mathrm{L}$ ). Another study by Zhang et al. (2004) evaluated the possible effects of environmental Cd exposure on pregnancy outcome, fetal growth and development. A higher cord blood Cd $(>0.40 \mu \mathrm{g} / \mathrm{L})$ level was associated with a $2.24 \mathrm{~cm}$ decline in neonatal birth height as compared to a lower cord blood Cd level $(\leq 0.40 \mu \mathrm{g} / \mathrm{L})$. They concluded that environmental $\mathrm{Cd}$ exposure significantly reduces neonatal birth height Equally, Wang et al. (2019) observed that maternal Cd exposure during middle gestational period increases the risk of small for gestational age infants in contrast to Cd exposure during early gestational stage. In addition, Lee et al. examined the correlation between self-reported infertility and heavy metals (blood $\mathrm{Pb}$ and $\mathrm{Cd}$ ) levels in US women. They compared the metal levels in infertile women and pregnant women. The result revealed low blood lead and cadmium levels were positively linked with self-reported infertility (blood lead $=0.50 \mu \mathrm{g} / \mathrm{dL}$ and blood cadmium $=0.26 \mu \mathrm{g} / \mathrm{L}$ ). The result suggests that even low level of blood $\mathrm{Cd}$ and $\mathrm{Pb}$ may be harmful to female fertility in women aged 20-39ys (Lee et al., 2020).

Cadmium exposure can also exert harmful effect on ovaries, placenta and uterus of females. Kumar and Sharma revealed that Cd exposure could either increases or inhibits the biosynthesis of progesterone, a hormone that is certainly linked with normal ovarian cyclicity and pregnancy maintenance Thus, Cd exposure was found to have an impact on ovarian and reproductive tract morphology, and extremely low doses were stated to stimulate ovarian luteal progesterone biosynthesis while high doses prevented it (Kumar and Sharma 2019). In another study, increased uterine wet weight, as well as endometrial thickness and endometrial stromal thickness, were observed in a group of rats during 3 days of exposure to $0.8 \mathrm{mg} \mathrm{kg}-1 \mathrm{Cd}$ in intraperitoneal injections (Rzymski et al., 2015). Also, Cd has been seen to mimic estrogen properties in uterus and female offspring experienced an earlier commencement of puberty and rise in the epithelial area and the number of terminal end buds in the mammary gland (Rehman et al., 2017). Additionally, experimental data has revealed that exposure to cadmium affects female fertility by altering pituitary function, ovulation, steroidogenesis, and fertilization (Lee et al., 2020). A study found Cd to also reduce the production of human chorionic gonadotropin and inhibited placental transmission of nutrients and oxygen to the fetus. Both the detection rate and exposure level of $\mathrm{Cd}$ in endometrial samples showed obvious differences between infertile and normal women (Tanrikut et al., 2014). Prevalence of Female Infertility

Infertility is a common medical problem that affects couples in developed countries. In Canada, total rate of fertility in Canada since 2009 has been reducing, for instance, from 1.68 to 1.54 children per woman in 2016 (Provencher et al., 2018). The National Survey of Family Growth (NSFG) report from 2015-2017 estimates $8.8 \%$ of married women aged 15-49 years in the US are infertile, $13.1 \%$ of women aged $15-49$ have impaired fecundity and $16.2 \%$ of married women with impaired fecundity defined as the inability to conceive and carry a baby to term. Among females in Britain, the estimated prevalence of infertility was $12.5 \%$ (Datta et al., 2016). Also, in Canada it was estimated that the prevalence of infertility among women aged 18-44 was $16 \%$ for heterosexual couples and China 1-18\% (Meng et al., 2015). Infertility in developed countries is associated with factors such as endometriosis, Chlamydia trachomatis infection and pelvic surgery as well as obesity, 
chemotherapy and some long-term chronic medical conditions (Bhattacharya Countries in Central African such as Angola, Central African Republic, et al., 2009). Also, infertility rate varies within countries and among countries. Equatorial Guinea, Gabon and Mozambique have high rate of primary and secondary female infertility. Also, in countries like Zimbabwe, secondary In developing and under developed countries, child bearing is a means of infertility rate accounts for $62 \%$ for women between the age of 25 and 49 years preserving a family's lineage and also guarantees some form of economic which is more than half of all reproductive aged women (Inhorn and Patrizio, security, in the sense that parents will rely on their children for support when 2015; Mascarenhas et al., 2012; Nachtigall 2006; Rutstein and Iqbal 2004).

aging. Therefore, most couples are under undue pressure to procreate

(Kaadaaga et al., 2014). Hence, female infertility and low birth rate are The high prevalent rates of female infertility in SSA may be as a result of high important public health issues with profound social, psychological, and exposure to environmental contaminants (heavy meals) and untreated economic consequences. The prevalence of infertility in female is much higher Reproductive Tract Infections (RTIs) in the region. Bede-Ojimadu et al. in developing countries than developed countries. The prevalence rate of (2018) revealed that heavy metal exposure levels among Sub-Saharan African infertility in developed countries ranges from $10-15 \%$ while in the SSA were generally higher than people in developed countries. In developed infertility prevalence rate has been notable high ranging from 10-30\%. Study nations, blood lead levels of the populace have continued to decrease over the reveals that 17 out of the 30 SSA countries studied, shows high rates of fertility years following regulatory bans on leaded gasoline and reduction in lead decline indicative of fertility transition (Sneeringer, 2009). Also, WHO content of consumer goods such as paints. On the contrary, reports from Subdemographic studies have identified that Sub-Saharan Africa countries has Saharan African indicate that blood lead level in this population have remained over $30 \%$ of women aged 25 - 49 years that suffer from secondary infertility elevated despite an official phase-out of leaded-gasoline in these countries (WHO, 2004). According to repeated cross-national surveys, infertility in (Bede-Ojimadu et al., 2018). Out of 33\% of women worldwide, 85\% of female is also prevalence in Central, West, and Southern Africa compared to women in SSA with infertility problems have their diagnosis attributed to low rates observed in East and North Africa. infections, (Inhorn and Patrizio 2015: Mascarenhas et al., 2012). Table 2 summarize the prevalence of female infertility in several countries.

Table 2: Prevalence of female infertility in developed and developing nations

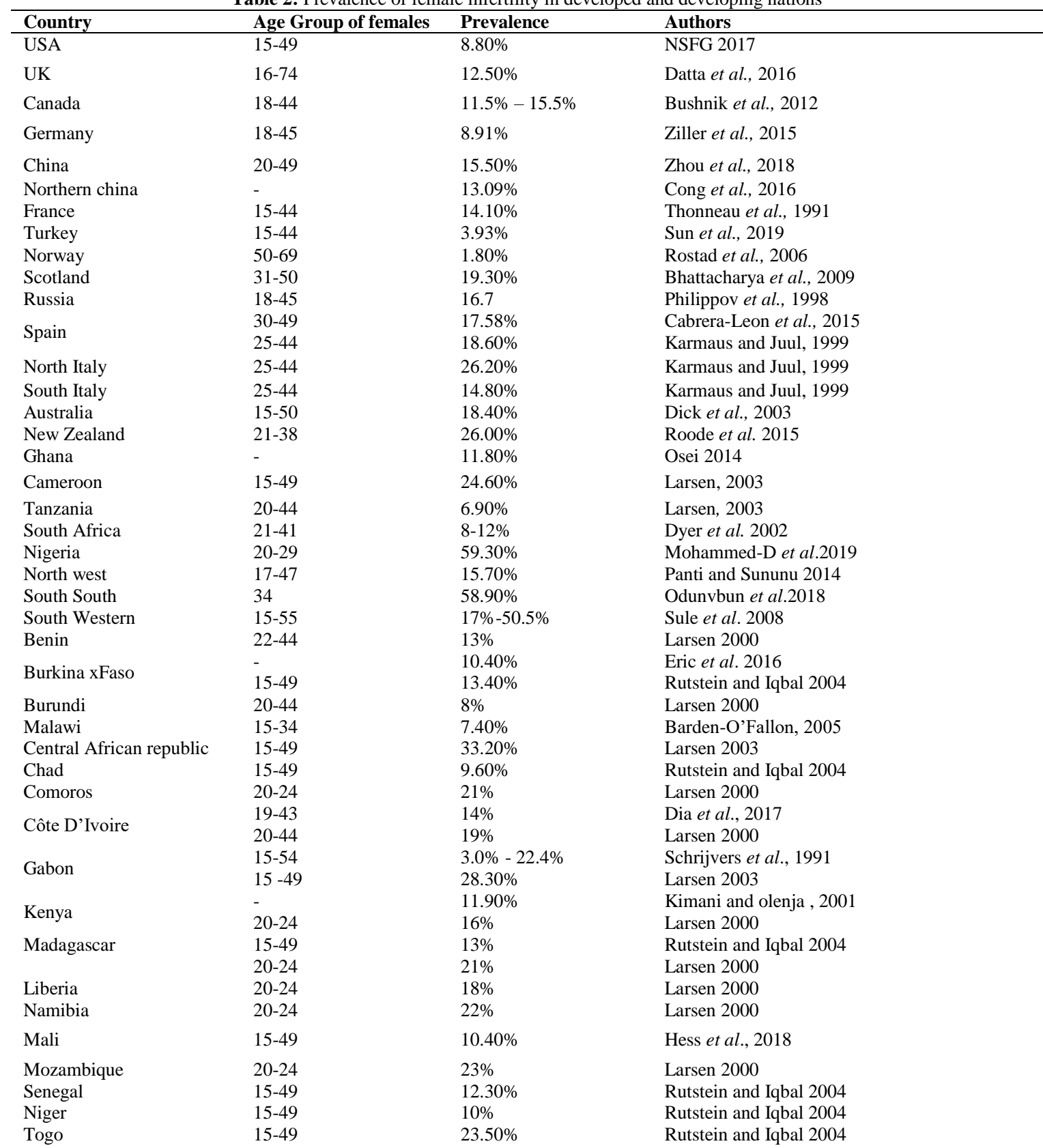




\begin{tabular}{llll} 
& $20-44$ & $5 \%$ & Larsen 2000 \\
Zambia & $15-49$ & $14.50 \%$ & Rutstein and Iqbal 2004 \\
Uganda & $15-49$ & $10.40 \%$ & Rutstein and Iqbal 2004 \\
Zimbabwe & & $10.96 \%$ & Rutstein and Iqbal 2004 \\
Morocco & $15-49$ & $19.20 \%$ & Rutstein and Iqbal 2004 \\
Iran & $18-45$ & $17.30 \%$ & Kazemijaliseh et al. 2015 \\
Peru & $20-49$ & $4.73 \%$ & Mirzaei et al. 2018 \\
India & $15-44$ & $3.60 \%$ & Sun et al. 2019 \\
Pakistani & $25-29$ & $8.90 \%$ & Katole and Saoji 2019 \\
Sudan & - & $14.20 \%$ & Kumar 2007 \\
\hline
\end{tabular}

\section{Oxidative Stress Implication in Female Infertility}

Oxidative stress (OS) takes place when the generation of reactive oxygen species (ROS) and other radical species overrules the scavenging capability of antioxidants, either by excess production of ROS or inadequate availability of antioxidants (Krajcir et al., 2008; Agarwal et al., 2012). Oxidative stres induces infertility in females through various mechanisms. Recent studies reveal that the disproportion between ROS and antioxidants could result to etiopathogenesis of pregnancy, endometriosis, polycystic ovarian disease, hydatidiform mole, tubal factor infertility and unexplained infertility (Agarwal et al. 2012; Merve and Elmas 2016; Diamanti-Kandarakis et al., 2017; Wojsiat 2017; Adeoye et al., 2018; Banerjee and Bhattacharya 2019). Excessive production of ROS may overwhelm the antioxidant defenses of follicular fluid, resulting in oocyte damage, reduced fertilization capacity, and precipitous pathologies affecting female reproduction.(Agarwal et al., 2005 Adeoye et al., 2018).
Oxidative stress induced hormonal imbalance may lead to damage cell membrane, cause cell apoptosis, damage proteins, lipid and nucleic acid, reduced growth and development of oocytes, increase mRNA in anterior pituitary, reduce follicular development and growth, poor oocytes quality, poor reproductive outcome, damage DNA, embryo fragmentation, implantation failure, abortion, ovarian aging and steroidogenesis, folliculogenesis, impaired placentation, congenital abnormalities and formation of numerous developmental abnormalities (Krajcir et al., 2008; Miler et al., 2010; Merve and Elmas 2016; Adeoye et al., 2018; Engwa et al., 2019). Thus, increasing studies indicate oxidative stress is one of the main causes of infertility in females (Agarwal et al., 2005; Ruder et al., 2009; Andriyas and Lal 2013; Banerjee and Bhattacharya 2019). Additionally, OS is implicated in the pathophysiology of pre-eclampsia and retards embryo development which damagingly modify fertilization capabilities, development of embryo and freely induced birth defects (Tranquilli et al., 2004). Oxidative stress can as well adversely affect the success of assisted fertility including IVF/ICSI and in-vitro maturation (Krajcir et al., 2008).

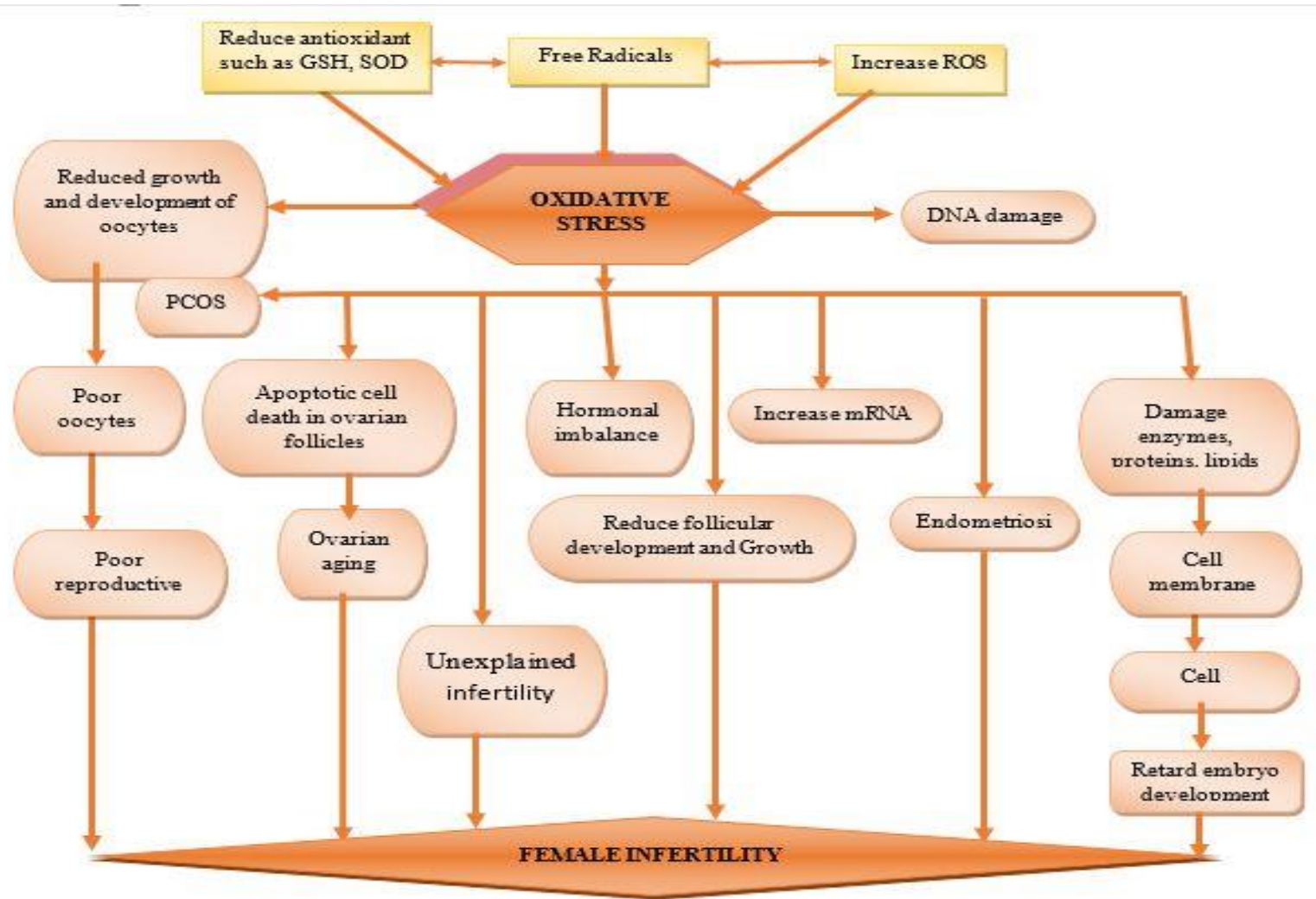

Figure 1: Effects of Oxidative Stress on female reproductive system

\section{Other Factors affecting female infertility}

Parameters such as age, obstetrical, reproductive history, nutrition, exercise psychological stress, smoking and drinking alcohol patterns, menstruation, BMI index, lifestyle and environmental factors are considered to be the major risk factors leading to infertility (Zhou et al., 2018, Cong et al., 2016).

\section{i.}

\section{Hyperprolactinemia}

Hyperprolactinemia occurs when the pituitary gland overproduces prolactin hormone in the blood. A study of 1607 female patients with medically treated hyperprolactinemia, showed prolactin hinders gonadotrophin secretion resulting in anovulation (Borght and Wyns, 2018).

ii.

Infection

Infectious agents have diverse modes of fecundity impairment. They can cause pelvic inflammatory disease and tubal Obstruction in females. Epidemiological figures suggest correlation between a past Chlamydia trachomatis infection and subfertility in women (Karinen et al., 2004). WHO estimated that the prevalence of Chlamydia trachomatis infections among 
adult females in 2005 was 4\%-6\% in all regions of the world, except the WHO Eastern Mediterranean and South-East Asia regions, where prevalence was below 2\% (Mascarenhas et al., 2012). Also, WHO, (2008), recorded the highest incidence of gonorrhoea to be in the Western Pacific Region (42.0 million cases), South-East Asia Region (25.4 million) and Africa Region (21.1 million).3.4 million cases of gonorrhoea were estimated in the European Region (53 countries). Neisseria gonorrhoea is a pathogen that affects the fallopian tube (Mitchell and Prabhu, 2013). Thus, the female reproductive system is negatively affected by infections.

\section{iii. Stress and Depression}

Stress and other psychological factors have a strong impact on reproductive cycles (Gopinath, 2013). According to a study illustrated in a nurse population, working longer hours (over $40 \mathrm{~h}$ /week) is linked with increased time to conceive, suggesting an association of fatigue or stress with decreased fertility (Gaskin et al., 2015). Impaired fertility might lead to depression in women trying to get pregnant; also it is likely that a history of depression could affect fecundity (Crawford et al., 2017).

\section{iv. Systemic disease}

It is commonly deemed that severe systemic disease, for example, sepsis or severe renal disease will thwart embryonic implantation. Diseases such as unstable diabetes, poorly managed celiac disease which is five times more common in females involved in unexplained infertility or recurring miscarriage than in the general population. The existence of thyroid antibodies in a woman with normal thyroid function is said to be connected with difficulty to conceive, recurring implantation failure of embryos and early pregnancy loss, potentially due to an unrecognized thyroid hormone deficiency or an autoimmune cause (Borght and Wyns, 2018).

\section{v. Lifestyle-related factors}

Lifestyle factors, such as regular exercise, frequent sexual intercourse, 2-3 times per week starting shortly after menses and following a healthy diet, could also help in achieving pregnancy (Borght and Wyns, 2018). Contrary, calorie restriction and extreme exercise may lead to a decrease in the regularity of ovulation, amenorrhea and poor endometrial development (Hart et al., 2016).

\section{vi. Cigarette smoking}

Cigarette smoking has a known effect on female fertility. Crawford et al (2017) reported likely difficulty staying pregnant in females who had ever smoked at least 100 cigarettes., Each phase of reproductive function, embryo transport, folliculogenesis, endometrial angiogenesis, steroidogenesis, endometrial receptivity, uterine blood flow and uterine myometrium are impaired in cigarette smoking females, as the smoke consists heavy metals, nitrosamines, polycyclic hydrocarbons and aromatic amines (Dechanet et al. 2011).

\section{vii. Marijuana and Alcohol intake}

Marijuana consumption in females' distorts menstrual cycle and decreased number of oocytes retrieved during in vitro fertilization. The probable mechanisms of action through which alcohol may impair fertility include an alcohol associated rise in estrogens leading to reduced FSH secretion and impaired ovulation (Borght and Wyns, 2018).

\section{viii. $\quad$ BMI}

Smurthwaite and Bagheri, (2017) stated that $21 \%$ of women in the globe are categorized as obese according to their body mass index (BMI). A recent study revealed that prolonged duration of infertility, age of females and BMI enhanced the generation of stress hormones and decreased antioxidant activity which augmented the risk of infertility (Alam et al., 2019). Data have also proven that women with higher BMI were more likely to have a delayed pregnancy or to be infertile (Meng et al., 2015; Bhattacharya et al., 2009; Wise et al., 2013). Cong et al., analysed the association between BMI values of women at childbearing age and the incidence of infertility and it was concluded that women with moderate BMI had the lowest incidence of infertility, and the overweight group was second. Underweight and obese women had high incidences of infertility, and the incidence of infertility was highest in the obesity group (Cong et al., 2016). Similarly, Borght and Wyns, stated women who are overweight are less likely to ovulate and to conceive spontaneously even after infertility care (Borght and Wyns, 2018). Moreover, a study carried out by Kumar revealed the success rate of IVF was about 31.8 per cent, and BMI was significantly reduced in females with positive outcome (Kumar et al., 2018).

\section{Conclusion}

Female infertility is a key public health problem with profound social, psychological, and economic consequences. The prevalence of female infertility is much higher in developing countries than in developed countries Occupational or environmental exposure to heavy metals such as lead, mercury, aluminium, manganese, cadmium and/or mixtures of metals had reduced fertility, induced oxidative stress, cause high prevalence and incidence rates of menstrual disorders. Heavy metal exposure has also been related to polycystic ovary syndrome, premenstrual syndrome, dysmenorrhoea (menstrual pain), amenorrhoea, early menopause, endometriosis, benign breast disorders and galactorrhoea, often associated with female infertility. In Sub Saharan Africa, the levels of heavy metal exposure among people were found to be higher than people in developed countries. This may be a contributory factor to the high prevalence of female infertility in this region. Thus, to manage female infertility exposures to heavy metal and other environmental toxicants should be eliminated, mostly in SSA

Funding

None.

\section{Availability of data and materials}

All data have been presented here.

\section{Competing interests}

The author(s) declare that they have no competing interests.

\section{References}

Adeoye, O., Johnson, O., Adeleke, O. \& Oyewopo, C. (2018). Review on the role of glutathione on oxidative stress and infertility. JBRA Assisted Reproduction; 22 (1):61-66.

Agarwal, A., Sajal, G. \& Rakesh. S. (2005). Oxidative stress and its implications in female infertility - a clinician's perspective. Reproductive BioMedicine. 11(5): 641-650.

Agarwal, A., Anamar, A., Beena, J. P., Amani, S. \& Sajal, G. (2012). The effects of oxidative stress on female reproduction: a review. Reproductive Biology and Endocrinology 10, 49. https://doi.org/10.1186/1477-7827-10-49.

Aker, A. M., Watkins, D. J., Johns, L. E., Ferguson, K. K., Soldin, O. P., Anzalota, L. V., Alshawabkeh, A. N., Cordero, J. F. \& Meeker, J. D. (2016). Phenols and parabens in relation to reproductive and thyroid hormones in pregnant women. Environ Res.151:30-37.

Alam, F, Taseer, A. K., Sofia, A. \& Rehana, R. (2019). Association of oxidative stress with female infertility - A case control study. Journal of the Pakistan Medical Association. 69(5): 627-631.

Altunkaynak, B. Z., Nilgun, A., Ahmad, Y., Muhammed, E. A., Aysin, P. T., Hayati, M. A. \& Bunyami, Ü. (2016). Effect of mercury vapor inhalation on rat ovary: Stereology and histopathology. Journal of Obstetrics and Gynaecology Research. 42(4), 410-416.

Andersen, A. (2008). Final Amended Report on the Safety Assessment of Methylparaben, Ethylparaben, Propylparaben, Isopropylparaben, Butylparaben, Isobutylparaben, and Benzylparaben as used in Cosmetic Products. International Journal of Toxicology 27(suppl 4):1-82

Banerjee, P., Bhattacharya, J. (2019). Impact of Oxidative stress on Infertility, with emphasis on infertility management strategies. Glob $J$ Fertil Res 4(1): 010-018.

Barbosa, C., Parente, A. M., De Souza, B., Bianco, B., Christofolini, D. M., (2011). The effect of hormones on endometriosis development. 63(4):375-86.

Barden-O'Fallon, J. (2005). Associates of Self-Reported Fertility Status and Infertility Treatment-Seeking in a Rural District of Malawi. Human Reproduction, 20(8):2229-2236.

Bede-Ojimadu, O. Amadi, C. N. and Orisakwe, O. E., (2018). Blood Lead Levels in Women of Child-Bearing Age in Sub-Saharan Africa: A Systematic Review. Frontiers in Public Health 6 | Article 367 doi: 10.3389/fpubh.2018.00367.

Bell, M. R. (2014). Endocrine-disrupting actions of PCBs on brain development and social and reproductive behaviours. Curr Opin Pharmacol. 19: 134-144.

Bhattacharya, S., Porter, M., Amalraj, E., Templeton, A., Hamilton, M., Lee, A. J. \& Kurinczuk, J. J. (2009). The epidemiology of infertility 
in the North East of Scotland. Human Reproduction, 24(12) 30963107 ,

Bjørklund, G., Maryam, D., Joachim, M. \& Jan, A. (2017). The toxicology of mercury: Current research and emerging trends Environmental Research 159:545-554. http://dx.doi.org/10.1016/j.envres.2017.08.051.

Borght, M. V. \& Wyns, C., (2018). Fertility and infertility: Definition and epidemiology. Clinical Biochemistry. https://doi.org/10.1016/j.clinbiochem.2018.03.012

Bushnik, T., Cook, J. L. A., Yuzpe, A., Tough, S. \& Collins, J. (2012). Estimating the prevalence of infertility in Canada. Human Reproduction, 27(3), 738-746.

Cabrera-León, A., Lopez-Villaverde, V., Rueda, M. \& Moya-Garrido, M. N. (2015). Calibrated prevalence of infertility in 30- to 49-yearold women according to different approaches: a cross-sectional population-based study, Human Reproduction, 30(11): 2677-2685

Chang, S. H., Cheng, B. H., Lee, S. L., Chuang, H. Y., Yang, C. Y., Sung, F. C. (2006). Low blood lead concentration in association with infertility in women. Environ Res; 101:380-386.

Choy, C. M., Lam, C. W., Cheung, L. T., Briton-Jones, C. M., Cheung, L. P., Haines, C. J. (2002). Infertility, blood mercury concentrations and dietary seafood consumption: a case-control study. BJOG.; 109(10):1121-5.

Cong, J., Li, P., Zheng, L. \& Tan, J. J. (2016). Prevalence and Risk Factors of Infertility at a Rural Site of Northern China. PLoS ONE 11(5): e0155563. doi:10.1371/journal.pone.0155563.

Craig, Z. R., Wang, W. \& Flaws, J. A. (2011). Endocrine-disrupting chemicals in ovarian function: effects on steroidogenesis, metabolism and nuclear receptor signalling. Reproduction 142; 633 646.

Crawford BR and DeCatanzaro D, (2012). Disruption of blastocyst implantation by triclosan in mice: Impacts of repeated and acute doses and combination with bisphenol-A. Reproductive Toxicology 34(4). DOI: 10.1016/j.reprotox.2012.09.008.

Crawford, S. Ruben, A. S., Sachiko, A. K. \& Violanda, G. (2017). Risks Factors and Treatment Use Related to Infertility and Impaired Fecundity Among Reproductive-Aged Women. J Womens Health (Larchmt). 26(5): 500-510.

Dai, Y., Xiaoyan, L., Jinghua, S. \& Jinhua, L. (2018). A review of the risk factors, genetics and treatment of endometriosis in Chinese women: a comparative update. Reproductive Health: 15:82.

Dallaire, R., Dewailly, É., Ayotte, P., Forget-Dubois, N., Jacobson, S. W., Jacobson, J. L. \& Muckle, G. (2013). Exposure to organochlorines and mercury through fish and marine mammal consumption: associations with growth and duration of gestation among Inuit newborns. Environ Int. 54:85-91.

Datta, J., Palmer, M. J., Tanton, C., Gibson, L. J., Jones, K. G., Macdowall, W., Glasier, A., Sonnenberg, P. \& Wellings, K. (2016). Prevalence of infertility and help seeking among 15000 women and men. Human Reproduction, 31(9) 2108-2118

Dechanet, C., Anahory, T., Mathieu Daude, J. C., Quantin, X., Reyftmann, L., Hamamah, S., Hedon, B., Dechaud, H. (2011). Effects of cigarette smoking on reproduction, Human Reproductive Update 17 (1) 76-95.

Dia, J. M., Sy, T., Bohoussou, E., Oyeladé, M., Okon, G., Guié, P. \& Anongba, S. (2017). Results of the multicentric management of infertility couples in Abidjan (Cote d'Ivoire). International Journal of Reproduction, Contraception, Obstetrics and Gynecology; 6(5):1753-1757.

Diamanti-Kandarakis, E., Olga, P., Eleni, A. K. \& Georgia, K. (2017). Nutrition as a mediator of oxidative stress in metabolic and reproductive disorders in women. European Journal of Endocrinology 176:2, 79-99.

Dick, M. L. B., Bain, C. J., Purdie, D. M., Siskind, V., Molloy, D. \& Green, A. C. (2003). Self-reported difficulty in conceiving as a measure of infertility, Human Reproduction, 18(12): 2711-2717,

Dyer, S. J., Abrahams, N., Hoffman, M., Vander Spuy, Z. M. (2002) Infertility in South Africa: women's reproductive health knowledge and treatment-seeking behaviour for involuntary childlessness, Human Reproduction, 17(6):1657-1662

Ehrlich, S., Williams, P. L., Missmer, S. A., Flaws, J. A., Ye, X. \& Calafat, A. M. (2012). Urinary bisphenol A concentrations and early reproductive health outcomes among women undergoing IVF. Hum. Reprod. 27, 3583-3592.

Elhussein, G.O., Mohamed, A. A., Suliman, S. O. \& Ishag, A. (2019). Epidemiology of infertility and characteristics of infertile couples requesting assisted reproduction in low resource setting in Africa, Sudan Fertility research and practice 5:7. https://doi.org/10.1186/s40738-019-0060-1

Engwa, G. A., Ferdinand, P. U., Nwalo, F. N., \& Unachukwu, M. N. (2019). Mechanism and Health Effects of Heavy Metal Toxicity in Humans. In O. Karcioglu, \& B. Arslan (Eds.), Poisoning in the Modern World - New Tricks for an Old Dog?. IntechOpen. https://doi.org/10.5772/intechopen.82511

Eric, S. N., Justine, B. \& Noël, P. J., (2016). Prevalence of the Infertility among Couples in Ouagadougou (Burkina Faso): a Populationbased Survey. The Open Public Health Journal 9:88-97.

Fang, J. L., Stingleyl, R., Beland, A., Fredrick, H. W., Lumpkins, L. D. \& Howard, P. (2010). Occurrence, efficacy, metabolism and toxicity of triclosan. Journal of Environmental Science and Health, Environmental Carcinogenesis and Ecotoxicology Reviews. 28(3), 147-171.

Fang, J. L., Vanlandingham, M., Juliar, B. E., Olson, G., Patton, R. E. \& Beland, F. A. (2015). Dose-response assessment of the dermal toxicity of triclosan in B6C3F1 mice. Toxicology Research $4867-$ 877.

Feng, Y., Pin, Z., Zhaobin, Z., Jiachen, S. Z. J. \& Bing, S. (2016). Endocrine disrupting effects of triclosan on the placenta in pregnant rats. PLoS One. 11(5): e0154758. doi: 10.1371/journal.pone.0154758.

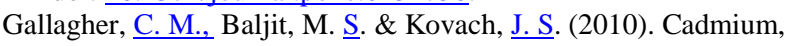
follicle-stimulating hormone, and effects on bone in women age 42 60 years, NHANES III 放 Cadmium, follicle-stimulating hormone, and effects on bone in women age 42-60 years, NHANES III. Environmental Research. 110, (1): 105-111.

Gopinath, C. (2013). Toxicology and pathology of female reproductive tract. Cell Biol Toxicol 29:131-141.

Hart, R. J., (2016). Physiological aspects of female fertility: role of the environment, modern lifestyle, and genetics, Physiol. Rev. 96 (3) 873-909.

Henriques, M. C., Loureiro, S., Fardilha, M., \& Herdeiro, M. T. (2019) Exposure to mercury and human reproductive health: A systematic review. Reproductive Toxicology (Elmsford, N.Y.), 85, 93-103.

Hess, R. F., Ross, R., Gililland, Jr J. L., (2018). Infertility, Psychological Distress, and Coping Strategies among Women in Mali, West Africa: A Mixed-Methods Study. Afr J Reprod Health; 22(1): 6072.

Hung, Y-C, Chao-Wei, K., Che-Chen, L., Yen-Nung, L, Bei-Yu W, ILing H, \& Wen-Long H, (2016). Chinese Herbal Products for Female Infertility in Taiwan A Population-Based Cohort Study. Medicine. 95, (11). doi: 10.1097/MD.0000000000003075.

Inhorn, M. C., \& Pasquale, P. (2015). Infertility around the globe: new thinking on gender, reproductive technologies and global movements in the 21st century. Human Reproduction, 21(4). 411426 ,

Kaadaaga, H. F., Ajeani, J., Ononge, S., Alele P. E., Nakasujja, N. \& Manabe Y. C. et al. (2014). Prevalence and factors associated with use of herbal medicine among women attending an infertility clinic in Uganda. BMC Complement Altern Med 14, 27. https://doi.org/10.1186/1472-6882-14-27

Kandaraki E, Antonis C, Sarantis L, Eleni P, Frangiscos E, Michael $\underline{K}$, Sotiria P, Dimitrios P, Diamanti-Kandarakis E, (2011). Endocrine disruptors and polycystic ovary syndrome (PCOS) elevated serum levels of bisphenol a in women with PCOS. J Clin Endocrinol Metab. 96 (3):480-484.

Karinen, L., Pouta, A., Hartikainen, A. L., Bloigu, A., Paldanius, M., Leinonen, M., Saikku, P., and Järvelin, M. R. (2004). Association between chlamydia trachomatis antibodies and subfertility in the northern Finland birth cohort 1966 (NFBC 1966), at the age of 31 years, Epidemiol. Infect. 132 (5): 977-984.

Karmaus, W. \& Juul, S. (1999). Infertility and subfecundity in population-based samples from Denmark, Germany, Italy, Poland and Spain. European Journal of Public Health. 9 (3). 229-235 
Katole, A. \& Saoji, A. V. (2019). Prevalence of primary infertility and its associated risk factors in urban population of central India: A community-based cross-sectional study. Indian Journal of Community Medicine, 44 (4): 337-341.

Kawaguchi, M., Morohoshi, K., Masuda, J., Watanabe, G., Morita, M. \& Imai, H. (2009). Maternal isobutyl-paraben exposure decreases the plasma corticosterone level in dams and sensitivity to estrogen in female offspring rats. Journal of Veterinary Medical Science, 71(8); 1027-1033.

Kazemijaliseh, H., Ramezani, T. F., Behboudi-Gandevani, S., Hosseinpanah, F., Khalili, D., \& Azizi, F. (2015). The Prevalence and Causes of Primary Infertility in Iran: A Population-Based Study. Global journal of health science, 7(6), 226-232.

Kezios, K. L., Liu, X., Cirillio, P. M., Kalantzi, O. I., Wang, Y., Petreas, M. X., Park J- Factor-Litvak P. et al., (2012). Prenatal polychlorinated biphenyl exposure is associated with decreased gestational length but not birth weight: archived samples from the Child Health and Development Studies pregnancy cohort. Environ Health 11, 49 https://doi.org/10.1186/1476-069X-11-49.

Kimani, V. N. \& Olenja J. M. (2001). Infertility: socio-cultural dimensions and the impact on women in selected communities in Kenya. Journal of African Anthropologist: 8; (2); 200-214.

Krajcir, N., Hyndhavi, C., Gupta, S. \& Agarwal, A. (2008). Female Infertility and Assisted Reproduction: Impact of Oxidative Stress. Current Women's Health Reviews, 4(1): 9-15.

Kumar, D. (2007). Prevalence of female infertility and its socioeconomic factors in tribal communities of Central India. Rural Remote Health; 7(2):456.

Kumar, S, Vineet, M., Riddhi, T., Mansi, G. Siva, P. Pratiksha, J. \& Yogendra, V. (2018). Role of environmental factors \& oxidative stress with respect to in vitro fertilization outcome. Indian Journal Med Res 148, 125-133.

Kumar, S. \& Sharma, A. (2019). Cadmium toxicity: effects on human reproduction and fertility. Rev Environ Health. https://doi.org/10.1515/reveh-2019-0016

Larsen, U. (2000). Primary and secondary infertility in sub-Saharan Africa. International Journal of Epidemiology, 29, (2): 285-291

Larsen, U. (2003). Infertility in central Africa. Tropical medicine and international health, 8(4):354-367.

Lee, T. W., Dae, H. K. \& Ji. Y. R., (2019). The effects of exposure to lead, cadmium and mercury on follicle-stimulating hormone levels in men and postmenopausal women: data from the Second Korean National Environmental Health Survey (2012-2014). Annals of Occupational Environmental Medicine.; 31:e21 doi.org/10.35371/aoem.2019.31.e21eISSN 2052-4374.

Lee, S., Jin-young, M. \& Kyoung-bok, M. (2020). Female Infertility Associated with Blood Lead and Cadmium Levels. International Journal of Environmental Research and Public Health. 17, 1794; doi: 10.3390/ijerph17051794.

Lei, H. L., Wei, H. J., Ho, H. Y., Liao, K. W. \& Chien L. C., (2015). Relationship between risk factors for infertility in women and lead, cadmium, and arsenic blood levels: A cross-sectional study from Taiwan. BMC Public Health.15: 1220.

Lemini, C., Jaimez, R., Avila, M. E., Franco, Y., Larrea, F. \& Lemus, A. E. (2003). In vivo and in vitro estrogen bioactivities of alkyl parabens. Toxicol Ind Health. 19(2-6):69-79.

Liu, J., Goyer, R. A., Waalkes, M. P. (2008). Toxic effects of metals. Casarett and Doull's Toxicology - The Basic Science of Poisons. McGraw-Hill, pp. 931-979.

Liu, S., Jiang, L., Meng, X., Han, X., Cheng, D., Zhang, T. \& Miao Y, (2014). Effects of Aroclor 1254 on In Vivo Oocyte Maturation in the Mouse. PLoS ONE 9 (7): e102064. doi:10.1371/journal.pone.0102064.

Ma, Y., He, X., Qi, K., Wang, T., Qi, Y. \& Cui, L. et al., (2019). Effects of environmental contaminants on fertility and reproductive health. Journal of Environmental Sciences, 77, 210-217.

Maeda, E., Katsuyuki, M., Yukiyo, K., Wataru, S., Hiromitsu, S. \& Takuya, I. et al., (2019). Associations of environmental exposures to methylmercury and selenium with female infertility: A case-control study. Environmental Research 168:357-363.
Mansur, A., Adir, M., Gil, M. Y., Ariel, H., Hila, G. \& Yuval, Y. et al., (2016). Does BPA alter steroid hormone synthesis in human granulosa cells in vitro? Hum Reprod.; 31(7):1562-1569.

Markey, C. M., Wadia, P. R., Rubin, B. S., Sonnenschein, C. \& Soto, A. M. (2005). Long-term effects of fetal exposure to low doses of the xenoestrogen bisphenol-a in the female mouse genital tract. Biol Reprod. 72(6):1344-1351.

Mascarenhas, M. N., Flaxman, S. R., Boerma T, Vanderpoel, S. \& Stevens, G. A. (2012). National, Regional, and Global Trends in Infertility Prevalence Since 1990: A Systematic Analysis of 277 Health Surveys. PLoS Med 9(12): e1001356. doi:10.1371/journal.pmed.1001356.

Maues, L. A. L., Macchi, B. M., Crespo-López, M. E., Nasciutti, L. E., Picanc, D. L. W. \& Antunes-Rodrigues et al., (2015). Methylmercury inhibits prolactin release in a cell line of pituitary origin. Brazilian Journal of Medical and Biological Research 48(8): 691-696.

Meng, Q., Aiguo, R., Le, Z., Jufen, L., Zhiwen, L., Yan, Y., Rong, L., Le, M. (2015). Incidence of infertility and risk factors of impaired fecundity among newly married couples in a Chinese population. Reproductive BioMedicine; 30, 92-100.

Merve, C. S. \& Elmas, Ç. (2016). The Effects of Oxidative Stress and Some of the Popular Antioxidants on Reproductive System: A Min Review. J Nutr Food Sci 6: 464. doi:10.4172/2155-9600.1000464.

Miler, E. A., Nudler, S. I., Quinteros, F. A., Cabilla, J. P., Ronchetti, S. A. \& Duvilanski, B. H. (2010). Cadmium induced-oxidative stress in pituitary gland is reversed by removing the contamination source. Hum Exp Toxicol. doi:10.1177/0960327110362703.

Mínguez-Alarcón, L. \& Gaskins, A. J. (2017). Female exposure to endocrine disrupting chemicals and fecundity: a review. Curr Opin Obstet Gynecol. 29(4): 202-211.

Mirzaei, M., Nasim, N., Razieh, D. F. \& Somaye, G. (2018). The prevalence of infertility in 20-49 years women in Yazd, 2014-2015: A cross-sectional study. Int J Reprod Biomed. 16(11): 683-688.

Miska-Schramm, A., Kapusta, J. \& Małgorzata, K. (2016). The Effect of Aluminum Exposure on Reproductive Ability in the Bank Vole (Myodes glareolus). Biol Trace Elem Res. Doi 10.1007/s12011-0160848-3

Mitchell, C. \& Prabhu, M. (2013). Pelvic inflammatory disease: current concepts in pathogenesis, diagnosis and treatment, Infect. Dis. Clin. N. Am. 27(4) 793-809.

Mok-Lin, E., Ehrlich, S., Williams, P. L., Petrozza, J., Wright, D. L. \& Calafat, A. M. et al., (2010). Urinary bisphenol a concentrations and ovarian response among women undergoing IVF. Int J Androl.; 33(2):385-393

Nachtigall, R. D. (2006). International disparities i access to infertility services. Fertility and Sterility. 85 (4):871-875

National Survey of Family Growth (NSFG), (2017). Centre for disease control and prevention. Available:

https://www.cdc.gov/nchs/fastats/infertility.htm. Accessed 10th September, 2020.

National Toxicology Program (2005). Butylparaben [CAS No. 94-26-8]. Review of Toxicological Literature: available http://ntp.niehs.nih.gov/ntp/htdocs/Chem_Background/ExSumPdf/b utylparaben_505.pdf. (Accessed 29th October 2020).

Nishihama, Y., Jun, Y., Ayaka, I., Shoko, K., Hideki, I., Miyuki Y, Daisuke $\mathrm{N}$ and Hiroaki S, (2016). Association between paraben exposure and menstrual cycle in female university students in Japan. Reproductive Toxicology. 63:107-113.

Odunvbun, W. O., Oziga, D. V., Oyeye, L. O. \& Ojeogwu, C. L. (2018). Pattern of infertility among infertile couple in a secondary health facility in Delta State, South South Nigeria. Trop J Obstet Gynaecol 35:244-248.

Osei, N. Y., (2014). Association of Childless Couples of Ghana (ACCOG). Facts Views Vis Obgyn. 6(2): 99-102.

Panti, A. A. \& Sununu, Y. T. (2014). The profile of infertility in a teaching Hospital in North West Nigeria. Sahel Med Journal 17:711.

Petro vi, M. L., Jo LMRL, Adrian, C., Erik, F., Diane, D. N., Alin, C. D., Ingrid, D. P., Peter, E. J. B. (2012). Endocrine-disrupting chemicals in human follicular fluid impair in vitro oocyte 
developmental competence, Human Reproduction, 27(4):10251033. https://doi.org/10.1093/humrep/der448.

Philippov, O. S., Radionchenko, A. A., Bolotova, V. P., Voronovskaya, N. I. \& Potemkina, T. V. (1998). Estimation of the prevalence and causes of infertility in Western Siberia. Bulletin of the World Health Organization, 76 (2): 183-187.

Pine, M., Lee, B. \& Dearth, R. (2005). Manganese acts centrally to stimulate luteinizing hormone secretion: a potential influence on female pubertal development. Toxicol Sci, 85: 880-885.

Provencher, C., Anne, M., Stacey, H. \& Carol, D. (2018). Fertility: Overview, 2012 to 2016. Report on the Demographic Situation in Canada Statistics Canada Catalogue no. 91-209-X

Quansah, R., Armah, F. A., Essumang, D. K., Luginaah, I., Clarke, E., Marfoh, K. \& Cobbina, S. J. et al., (2015). Association of arsenic with adverse pregnancy outcomes/infant mortality: a systematic review and meta-analysis. Environ Health Perspect 123:412-421;

Rahman, S. N., Fatima, P., Chowdhury, A. Q. \& Rahman, M. W. (2013). Blood level of lead in women with unexplained infertility Mymensingh Med J. 22(3):508-512.

Rashtian, J., Chavkin, D. E., \& Merhi, Z. (2019). Water and soil pollution as determinant of water and food quality/contamination and its impact on female fertility. Reproductive Biology and Endocrinology, 17(1), 5. https://doi.org/10.1186/s12958-018-0448-5

Rattan, S., Changqing, Z., Catheryne, C., Sharada, M., Emily, B. \& Jodi, A. F. (2017). Exposure to endocrine disruptors during adulthood: consequences for female fertility. Journal of Endocrinology. 233, 109-129

Rehman, K., Fiza, F., Iqra, W., Muhammad, S. \& Hamid, A. (2017). Prevalence of exposure of heavy metals and their impact on health consequences. Journal of Cellular Biochemistry 119:157-184.

Roode, T. V., Nigel, P. D., Alida, A. R. \& Wayne, R. G. (2015). Cumulative incidence of infertility in a New Zealand birth cohort to age 38 by sex and the relationship with family formation. Fertility and Sterility, 103 (4): 1053-1058.

Rostad, B., Schei, B. \& Sundby, J. (2006). Fertility in Norwegian women: Results from a population-based health survey. Scandinavian Journal of Public Health, 34(1), 5-10.

Rutstein, S. O. \& Iqbal, H. S. (2004). Infecundity, Infertility, and Childlessness in Developing Countries. DHS Comparative Reports No. 9. Calverton, Maryland, USA: ORC Macro and the World Health Organization

Rzymski, P., Katarzyna, T., Rzymski, P., Barbara, P., Tomasz, O. \& Maciej, W. (2015). Impact of heavy metals on the female reproductive system. Annals of Agricultural and Environmental Medicine 22(2): 259-264.

Schrijvers, D., Dupont, A. \& Meheus, A. (1991). Prevalence and type of infertility in Gabon. Ann. Soc. belge Med. Trop, 71:317-323.

Sengupta, P., Banerjee, R., Nath, S., Das, S. \& Banerjee, S. (2015). Metals and female reproductive toxicity. Human and Experimental Toxicology. 34(7); 679-697.

Shaheen, R., Subhan, F., Sultan, F. \& Subhan, K. (2010). Prevalence of infertility in a cross section of Pakistani Population. Pakistan Journal of Zoology, 42(4): 389-393.

Shen, Y., Zheng, Y., Jiang, J., Liu, Y., Luo, X. \& Shen, Z. et al., (2015). Higher urinary bisphenol A concentration is associated with unexplained recurrent miscarriage risk: evidence from a casecontrol study in eastern China. PloS one, 10(5), e0127886. https://doi.org/10.1371/journal.pone.0127886

$\underline{\text { Smith, K. W., Irene, S., Irene, D., Ehrlich, S., Paige, L. W. \& Antonia, }}$ M. C. et al., (2013). Urinary Paraben Concentrations and Ovarian Aging among Women from a Fertility Centre. Environ Health Perspect 121(11-12): 1299-1305.

Smurthwaite, K. \& Bagheri, N. (2017). Using geographical convergence of obesity, cardiovascular disease, and type 2 diabetes at the neighbourhood level to inform policy and practice, Prev. Chronic Dis. 14 E91.

Sneeringer, S. E. (2009). Fertility Transition in Sub-Saharan Africa: A Comparative Analysis of Cohort Trends in 30 Countries. DHS Comparative Reports No. 23. Calverton, Maryland, USA: ICF Macro.

Street, M. E., Sabrina, A., Sergio, B., Ernesto, B., Alessandra, C. \& Cecilia, C. et al., (2018). Current Knowledge on Endocrine
Disrupting Chemicals (EDCs) from Animal Biology to Humans, from Pregnancy to Adulthood: Highlights from a National Italian Meeting. International Journal of Molecular Sciences 19, 1647. https://doi.org/10.3390/ijms19061647

Sule, J. O., Erigbali, P. \& Eruom, L. (2008). Prevalence of Infertility in Women in a South-western Nigerian Community. African Journal of Biomedical Research, 11; 225 - 227.

Sun, H., Gong, T. T., Jiang, Y. T., Zhang, S., Zhao, Y. H., \& Wu, Q. J. (2019). Global, regional, and national prevalence and disabilityadjusted life-years for infertility in 195 countries and territories, 1990-2017: results from a global burden of disease study, 2017. Aging, 11(23), 10952-10991.

Susko, M. L., Bloom, M. S., Neamtiu, I. A., Appleton, A. A., Surdu, S. \& Pop, C. (2017). Low-level arsenic exposure via drinking water consumption and female fecundity - A preliminary investigation. Environmental Research 154,120-125.

Tang, N. \& Zhu, Z. Q. (2003). Adverse reproductive effects in female workers of lead battery plants. International Journal of Occupational Medicine and Environmental Health; 16(4): 359 361.

Tanrıkut, E., Karaer, A., Celik, O., Celik, E., Otlu, B. \& Yilmaz, E. et al., (2014). Role of endometrial concentrations of heavy metals (cadmium, lead, mercury and arsenic) in the aetiology of unexplained infertility. European Journal of Obstetrics \& Gynecology and Reproductive Biology. 179:187-190.

Taxvig, C., Vinggaard, A. M., Hass, U., Axelstad, M., Boberg, J. \& Hansen, P. R. et al., (2008). Do parabens have the ability to interfere with steroidogenesis? Toxicological Sciences. 106(1), 206-213.

Thonneau, P., Sophie, M., Anne, T., Marie-Laure, F., Béatrice, D. \& Jacques, L. et al., (1991). Incidence and main causes of infertility in a resident population (1 850000$)$ of three French regions (19881989), Human Reproduction, 6 (6): 811-816.

Tranquilli, A. L., Bezzeccheri, V., Giannubilo, S. R., Scagnoli, C., Mazzanti, L. \& Garzetti, G. G. (2004). Amniotic vascular endothelial growth factor (VEGF) and nitric oxide (NO) in women with subsequent preeclampsia. Eur J Obst Gynecol Reprod Biol. 113:17-20.

Vélez, M. P., Arbuckle, T. E. \& Fraser, W. D. (2015). Female exposure to phenols and phthalates and time to pregnancy: the MaternalInfant Research on Environmental Chemicals (MIREC) Study. Fertility and Sterility; 103(4):1011-1020.e2.

Vo, T. B., Yeong-Min, Y., Kyung-Chul, C. \& Eui-Bae, J. (2010). Potential estrogenic effect(s) of parabens at the prepubertal stage of a postnatal female rat model. Reproductive Toxicology 29:306-316.

Wang, J., Chi, L., Masayuki, F., Guoqing, T., Qinxiu, Z. \& Xiao-Kang, L. et al., (2019). Stem Cells as a Resource for Treatment of Infertility-related Diseases. Current Molecular Medicine: 19, 539546

Wang, N., Yue, S., Yanzhu, Z., Hansong, Z., Bing, S. \& Hao, S. et al., (2012). Effects of Subchronic Aluminium Exposure on the Reproductive Function in Female Rats. Biological Trace Element Research 145(3):382-387.

Weller, B. K., Senay, U. A. \& Melike, S. M. (2017). Effects of Cadmium on Female Fertility Parameters: An Experimental Study. Ethno Med, 11(1): 63-69.

Wise, L. A., Palmer, J. R. \& Rosenberg, L. (2013). Body size and timeto-pregnancy in black women. Hum Reprod. 28(10): 2856-2864.

World Health Organization (2018). Global Prevalence of Infertility, Infecundity and Childlessness. http://www.who.int/reproductivehealth/topics/infertility/burden/en/

World Health Organization (2008- 2012). Global incidence and prevalence of selected curable sexually transmitted infections. ISBN: 9789241503839

Yang, Y. S., Kwon, J. T., Shim, I. \& Kim, H. (2015). Evaluation of toxicity to triclosan in rats following 28 days of exposure to aerosol inhalation. Regulatory Toxicology and Pharmacology; 160(2). DOI: 10.1016/j.yrtph.2015.01.004.

Zhang, Y. L., Yong, Cheng, Z., Ji-Xian, W., Hong-Da, Z., Qing-Fen, L. \& Ya-Guang, F. et al., (2004). Effect of Environmental Exposure to Cadmium on Pregnancy Outcome and Fetal Growth: A Study on Healthy Pregnant Women in China. Journal of Environmental 
Science and Health, 39 (9). .https://doi.org/10.1081/ESE200026331.

Zheng, G., Wang, L., Guo, Z., Sun, L., Wang, L. \& Wang, C. et al., (2015). Association of Serum Heavy Metals and Trace Element Concentrations with Reproductive Hormone Levels and Polycystic Ovary Syndrome in a Chinese Population. Biol Trace Elem Res. DOI 10.1007/s12011-015-0294-7.

- Thank you for publishing with us.
Zhou, Z., Zheng, D., Wu, H., Li, R., Xu, S. \& Kang, Y. et al., (2018). Epidemiology of infertility in China: a population-based study. BJOG; 125, 432-441.

Ziller, V., Hadji, P., Thielscher. C., Ziller, M. \& Kostev, K. (2015). Prevalence of female subfertility in German gynaecological practices. Journal of Gynaecological Endocrinology. 29(8): https://doi.org/10.31S09/09513590.2013.798274. 